\title{
Long-distance seed dispersal by wind: disentangling the effects of species traits, vegetation types, vertical turbulence and wind speed
}

Received: 3 April 2013/ Accepted: 10 April 2014/Published online: 17 May 2014

(C) The Author(s) 2014. This article is published with open access at Springerlink.com

\begin{abstract}
Long-distance dispersal (LDD) of plant seeds by wind is affected by functional traits of the species, specifically seed terminal velocity and height of seed release above the vegetation cover (HAC), as well as by the meteorological parameters wind speed and vertical turbulence. The relative importance of these parameters is still under debate and the importance of their variability in vegetation types, sites and years has only rarely been quantified. To address these topics, we performed simulation studies for different vegetation types, sites, years and plant species with PAPPUS, a process based trajectory model. We found that LDD (measured in terms of migration rates) was higher in forests compared to open landscapes. Forests also showed greater between-year variability in LDD. Terminal velocity had an effect on LDD in both vegetation types, while the effect of HAC was significant only in the open landscape. We found considerable differences in how vertical turbulence and wind speed affect LDD between species and vegetation types: In the open landscape the strength of the positive relationship between vertical turbulence and LDD generally decreases with terminal velocity, whereas it increases in forests. The strength of the predominantly positive effect of wind speed on LDD increases with terminal velocity in both vegetation types, while in for-
\end{abstract}

Electronic supplementary material The online version of this article (doi:10.1007/s11284-014-1142-5) contains supplementary material, which is available to authorized users.

F. Heydel $(\bowtie) \cdot$ S. Cunze $\cdot$ O. Tackenberg

Institute of Ecology, Evolution and Diversity, Goethe University, Max-von-Laue-Str. 13, 60438 Frankfurt am Main, Germany

E-mail: felix.heydel@gmail.com

S. Cunze

Biodiversity and Climate Research Centre Frankfurt (BiK-F),

Senckenberganlage 25, 60325 Frankfurt am Main, Germany

M. Bernhardt-Römermann

Institute of Ecology, Friedrich-Schiller-University Jena,

Dornburger Str. 159, 07743 Jena, Germany ests we found even negative relationships for species with low terminal velocity. Our results generally suggest that the effects of vertical turbulence and wind speed on LDD by wind diverge for species with different functional traits as well as in different vegetation types.

Keywords Anemochory · Functional traits - Release height $\cdot$ Terminal velocity $\cdot$ Wind dispersal model

\section{Introduction}

Seed dispersal and plant migration strongly affect plant diversity (Pitelka et al. 1997; Parmesan and Yohe 2003; Normand et al. 2011). The rate of future climate change is that high, that the spread rates of most plant species seem to be much lower than is required in order to keep pace with the climate induced range shifts (Neilson et al. 2005; Cunze et al. 2013). Primarily, seed dispersal affects plant spread in space and time (Clark et al. 1998; Cain et al. 2000; Higgins et al. 2003). Long-distance dispersal (LDD) of seeds is often driven by extreme events, like rare meteorological weather conditions, large migratory animals or transport by humans (Nathan et al. 2008). LDD of seeds shapes many important and fundamental processes in plant ecology and evolution. Altogether gene flow between populations, local adaptation, spatial dynamics of plant species, communities and ecosystems are affected by LDD (e.g. Kawecki and Ebert 2004; Nathan et al. 2008; Öster et al. 2009; Latzel et al. 2011).

Regarding LDD by wind, weather conditions like convective updrafts or storms seem to play an important role. Currently the role of meteorological conditions promoting LDD is under debate: convective updrafts (Tackenberg et al. 2003b) and horizontal wind speed (Jongejans and Schippers 1999; Nathan et al. 1999, 2002) were both proposed to play an important role. Unfortunately, previous studies focus on one or few species only, address either open landscapes or forests, 
refer to different time periods and use different simulation models. Consequently it remains unclear whether the observed and partly opposing results originate from differences between studied vegetation types, plant species, meteorological conditions or the used simulation models.

To gain general insights when addressing LDD by wind, it seems important to consider a broad range of different meteorological conditions, because of the rarity and stochasticity of conditions promoting LDD (Nathan 2006). As LDD data are difficult to acquire, the effect of the variability between vegetation types, sites and years on LDD by wind was yet only analysed in few studies. As one of the first, Houle (1998) studied temporal variation in spatial patterns of dispersed seeds empirically and found significant variation between years. Nathan et al. (2000) additionally addressed the effect of distance on LDD and found highest variation in dispersal patterns far away from the seed source.

The meteorological conditions that affect LDD by wind are not only related to the macroclimate but also depend on the structure of the vegetation type, topography and landscape texture. For example, LDD is thought to increase with landscape openness (Nathan et al. 2008). Attempts to quantify differences in LDD between vegetation types have rarely been made (e.g. Fort and Richards 1998; Tackenberg and Stöcklin 2008).

The timing of seed abscission is a further plant-controlled trait having a great impact on LDD by wind (Greene 2005; Schippers and Jongejans 2005; Greene and Quesada 2011). Seeds of many plant species are only released when the wind speed exceeds a certain release wind speed threshold, which actually leads to larger dispersal distances.

Empirical studies often use seed traps and thus regularly fail to quantify LDD (Greene and Calogeropoulos 2002). Process based trajectory models have the potential to overcome this limitation (Nathan et al. 2011). Especially for LDD by wind, process based models provide good estimates of how far seeds are expected to disperse (Nathan et al. 2002; Tackenberg 2003; Soons et al. 2004; Horn et al. 2012) and therefore supply the most accurate results of plant spread $(\mathrm{Ku}-$ parinen 2006). In these models, seed terminal velocity during the fall (VTERM) and the height of seed release above the vegetation cover (HAC) are often considered as vital plant traits for LDD by wind (Nathan et al. 2002; Tackenberg 2003). Although the dispersed unit may also be a fruit or another morphological unit, we will use the term 'seed' in this study for reasons of simplification. Dispersal within the canopy seems less important and is therefore often ignored when focusing on LDD (Nathan et al. 2002). Accordingly, plant individuals dispersing their seeds above the vegetation canopy are regarded as "hot spots" of LDD by wind (Horn et al. 2001; Bohrer et al. 2008).

In this study we use a simulation approach in order to disentangle the effects of the plant traits VTERM and
HAC, the meteorological parameters vertical turbulence and wind speed, between-year variability, and structure of the vegetation type (open landscape vs. forest) on LDD by wind. Specifically, we explore the following questions: (1) Does LDD differ between vegetation types? (2) Does the effect of VTERM and HAC on LDD differ between vegetation types? (3) Does LDD differ between years? (4) How do the effects of vertical turbulence, wind speed, vegetation type, VTERM and HAC interact?

\section{Methods}

\section{Modelling wind dispersal using PAPPUS}

We used PAPPUS, a mechanistic wind dispersal model which simulates trajectories of individual seeds (for a detailed description see Tackenberg 2003). Trajectory models simulate particle trajectories so that temporary airflows (like e.g. vertical turbulence) directly affect the dispersing particle during its flight. Trajectory models provide an important increase in realism and are preferable for modelling wind dispersal over short and long distances (Kuparinen 2006). PAPPUS was validated (following Rykiel 1996) by comparing dispersal distance spectra generated by simulations with empirically observed distance spectra from release experiments in different landscapes and under various weather conditions (Tackenberg 2003). The empirically observed spectra matched reasonably well with the modelled dispersal distance spectra, especially under weather conditions with convective turbulence.

As most trajectory models, PAPPUS uses two species-specific traits to characterize plant species, namely HAC and VTERM. In the simulations, the flight of a seed is subdivided into time periods of $0.1 \mathrm{~s}$, and its movement is calculated separately for each period as the sum of VTERM and the wind vector (horizontal wind speed $=$ WIND, direction and vertical wind speed). The decrease of wind speed with declining height above ground is taken into account by a logarithmic vertical wind profile, which is regulated by the roughness of the vegetation cover (e.g. McCartney 1990). The simulation stops once the seed falls below the closed vegetation canopy. In consequence, LDD occurs only while seeds are above the vegetation canopy (as also argued by Nathan et al. 2002).

The course of the wind vector during the flight of a seed is permanently changing due to vertical and horizontal turbulence (Mazzoni 1996). PAPPUS incorporates turbulence by deriving the course of the wind vector from high-frequency measurements of the wind vector during the period the simulations refer to. This empirical component allows realistic consideration of convective updrafts, which have been proved to be an important determinant of LDD by wind in empirical studies (Tackenberg 2003) as well as in simulation studies (Tackenberg et al. 2003b). 
The simulations performed with PAPPUS result in single dispersal events which constitute discrete frequencies of dispersal distances (i.e. the dispersal kernel) when repeating simulations.

\section{Species traits}

The effect of VTERM and HAC on LDD was studied on 18 model species that were characterised by unique combinations of both traits. These trait combinations cover a wide range of relevant values, specifically VTERM of $0.1,0.2,0.4,0.8,1.6$ and $3.2 \mathrm{~m} \mathrm{~s}^{-1}$ and HAC of $0.1,0.4$ and $1.6 \mathrm{~m}$, so that results can easily be transferred to a wide range of 'real' plant species (see discussion for respective examples). In order to ensure direct comparability between open landscape and forest, VTERM and HAC were defined using the same values for both vegetation types. Using HAC instead of the height of seed release above ground implies that seeds of species with identical traits have identical falling heights (as the simulation only addresses dispersal above the canopy). A HAC of $0.4 \mathrm{~m}$ stands for example for a herb from open landscapes overtopping low vegetation cover with $0.4 \mathrm{~m}$ as well as for a tree overtopping the forest canopy with that height. In consequence, the results for different vegetation types are directly comparable, as the simulations refer to homogeneous landscapes, which are completely covered by the respective vegetation type.

Simulation of dispersal kernels in different environments

The most important meteorological parameter affecting seed dispersal is the course of the wind vector (wind direction, vertical and horizontal wind speed) and its fluctuations, i.e. turbulence. PAPPUS uses high-frequency measurements of the wind vector with ultrasonic anemometers to simulate the course of the wind vector. The measurements of the wind vector incorporated in our simulations address two vegetation types (open landscape and spruce forest). The measurements originate from the years 2005 and 2006 and were taken by Grünwald and Bernhofer (2007), Lehner (2008) and Prescher et al. (2010). All measured data were processed to a temporal resolution of $10 \mathrm{~Hz}$. In each vegetation type, measurements were performed on two different sites (open landscape: site 1, 2 and forest: site 3,4). For each site, the original wind data was standardised to an equal height above the vegetation cover using the logarithmic windprofile (see also Tackenberg 2003). Further parameters of the turbulence measurements are provided in Table $\mathrm{S} 1$ in the electronic supplementary material (ESM).

For each species, vegetation type, and site we calculated 200 trajectories for each hour of the day with randomly chosen starting times within the hour. Subsequently, we aggregated these data into weekly dispersal kernels that build the basis for the further analyses. Each weekly kernel consists of 30,000 trajec- tories which were randomly chosen from all trajectories that were available for the respective week. The simulations refer to landscapes that are flat and completely covered by the respective vegetation type.

Two meteorological parameters were calculated for each hour and week in order to reveal the relationship between wind speed, vertical turbulence, and LDD by wind. First, we calculated WIND as the mean horizontal wind speed in $0.4 \mathrm{~m}$ height above the canopy. Second, we calculated TURB in that height as the proportion of LDD relevant updrafts. TURB is a measure of the intensity of vertical turbulence and is calculated as the proportion of time, during which updrafts of a vertical wind speed that is greater than the VTERM of the respective species occur (Tackenberg 2003). The timeperiod for which the vertical wind speed is averaged is $100 \mathrm{~m}$ divided by the mean horizontal wind speed. Hence, updrafts of that strength and duration are capable of prolonging the flight of a seed to reach a distance of $100 \mathrm{~m}$ without losing altitude in relation to the initial release height. TURB has already been used to assess the relevance of updrafts (Tackenberg et al. 2003b).

\section{Migration rates as a measure of LDD}

In order to generate a measure of LDD, we calculated migration rates following the approach presented by Clark et al. (2001). Unlike many other commonly applied measures of LDD, the calculated migration rates do not refer to a pre-determined dispersal distance (see also the discussion section). In fact, the migration rates are highly sensitive to the rare long-distance dispersal events of the species (i.e. the tail of the species' dispersal kernel). Migration rates (in $\mathrm{m} \mathrm{year}^{-1}$ ) were calculated from the weekly dispersal kernels as the expected value of the maximum of a random sample of the size of the number of offspring at seed release $\left(\mathrm{R}_{0}\right)$, divided by the generation time ( $\mathrm{T}$, see also Higgins et al. 2003). $R_{0}$ was set 100 and $T$ to 1 .

\section{Data analysis}

To test whether the calculated migration rates can generally be used as a measure of LDD, we tested the strength of relationship between migration rates and an alternative measure of LDD. Therefore, we exemplarily calculated the Spearman correlation coefficient $\rho$ between the proportion of seeds exceeding $100 \mathrm{~m}$ reference distance (further referred to as 'alternative measure of LDD') and the calculated migration rates. In order to simplify our argument, we will mostly refer to LDD rather than to migration rates in the following.

The availability of wind data varied between vegetation types, sites, and years (for weekly values of TURB and WIND of the four sites and both years see Table S2 in the ESM). Thus, we generated customized datasets based on the same periods. These subsets were compiled in respect of sample size and comprised weeks from the 
whole year. This subsetting ensures that the comparison between vegetation types is not biased by the consideration of different periods of the year with different weather conditions.

The effect of vegetation types, sites, VTERM and HAC on LDD was analysed using 17 identical weeks from the year 2006 (dataset 1, see Table S2). The analysis of the between-year effect on LDD was based on 12 and 19 identical weeks from both years 2005 and 2006 (dataset 2 and 3 for open landscape sites and forest sites, respectively). The analyses of the relationship between the calculated migration rates and the alternative measure of LDD, as well as the effect of WIND and TURB on LDD, were both based on 49 and 51 weeks from 2005 and 2006 (dataset 4 and 5 for open landscape sites and forest sites, respectively).

Statistical analyses were done using generalised linear models (GLM) of the gamma error distribution family.

First, we analysed the effect of vegetation type with a GLM containing the variables vegetation type (explanatory variable) and LDD (dependent variable). Subsequently, we studied the effects of sites, VTERM and HAC on LDD with separate GLMs for each vegetation type. To analyse the between-year effect on LDD, four separate GLMs (one model for each site) were set up containing VTERM and year as explanatory variables. In order to analyse the between-year effect on LDD for each species separately, here VTERM was treated as a factor.

Models were simplified using backward selection of the non-significant variables until the final minimal adequate model contained only significant terms $(\mathrm{p}<0.05)$ and a minimal Akaike Information Criterion (AIC) was obtained (Crawley 2007).

To analyse the effect of WIND and TURB on LDD and to detect differences between species and vegetation types, we calculated Spearman correlation coefficients $\rho$ between these parameters and LDD separately for each VTERM $($ HAC $=0.4 \mathrm{~m})$ and vegetation type.

All statistical analyses were performed with $\mathrm{R} 2.14 .1$ (R Core Team 2012).

\section{Results}

\section{Migration rates as a measure of LDD}

The analysis of the relationship between calculated migration rates and the alternative measure of LDD showed that both are highly correlated (Spearman's $\rho=0.965 ; \mathrm{p}<0.001)$.

\section{Vegetation types and sites}

We found significantly higher LDD in forest sites than in open landscape sites $(\mathrm{p}<0.001$, Table 1; Fig. 1). In forest sites, mean TURB was about 24 times higher and mean WIND about $30 \%$ higher than in open landscape sites (Table 2).

The effect of site on LDD was significant in both vegetation types. Between forest sites absolute differences in median migration rates were bigger than between open landscape sites (Fig. 1), whereby relative differences in LDD between sites were greater in open landscape sites than in forest sites. In open landscape sites, we found $60 \%$ greater median migration rates in site 1 than in site 2 while in forest sites we found $38 \%$ greater median migration rates in site 4 than in site 3 . Similarly, relative between-site differences in TURB and WIND (Table 2) were greater between the open

Table 1 Summary statistics of three generalised linear models (GLM; Vegetation type, Open landscape and Forest) of the gamma error distribution family

\begin{tabular}{|c|c|c|c|c|}
\hline & Estimate & Std. error & t-value & p-value \\
\hline \multicolumn{5}{|l|}{ Vegetation type } \\
\hline Open landscape & 0.00226 & 0.00023 & 9.820 & $<0.001 * * *$ \\
\hline Forest & -0.00155 & 0.00022 & -6.452 & $<0.001 * * *$ \\
\hline \multicolumn{5}{|l|}{ Open landscape } \\
\hline Site 1 & -0.00890 & 0.00156 & -5.701 & $<0.001^{* * *}$ \\
\hline Site 2 & 0.00225 & 0.00092 & 2.438 & $0.015^{*}$ \\
\hline VTERM & 0.09241 & 0.01546 & 5.978 & $<0.001^{* * *}$ \\
\hline HAC & 0.00411 & 0.00107 & 3.850 & $<0.001^{* * *}$ \\
\hline VTERM:HAC & -0.04230 & 0.01055 & -4.012 & $<0.001^{* * *}$ \\
\hline \multicolumn{5}{|l|}{ Forest } \\
\hline Site 3 & 0.00006 & 0.00005 & 1.997 & 0.231 \\
\hline Site 4 & -0.00015 & 0.00004 & -4.102 & $<0.001 * * *$ \\
\hline VTERM & 0.00316 & 0.00020 & 15.683 & $<0.001^{* * *}$ \\
\hline $\mathrm{HAC}$ & 0.00006 & 0.00003 & 1.917 & 0.056 \\
\hline VTERM:HAC & -0.00080 & 0.00017 & -4.709 & $<0.001 * * *$ \\
\hline
\end{tabular}

The first model (vegetation type) analyses the effect of vegetation types on migration rates. The second and third model (open landscape and forest, respectively) analyse the effect of site, seed terminal velocity (VTERM) and height of seed release above the vegetation cover $(\mathrm{HAC})$ on migration rates separately for open landscape and forest. Each model bases on 1224 migration rates $(17$ weeks $\times 18$ species $\times 4$ sites $\times 1$ year). It must be taken into account, that the model coefficients of a GLM using the gamma error distribution family can only be interpreted if the coefficient (e.g. estimate) is transformed into its reciprocal. The table includes estimates, standard errors (Std. Error), $\mathrm{t}$ - and corresponding $\mathrm{p}$-values for all significant interactions and variables

Different symbols indicate significant levels with $* * * \mathrm{p}<0.001,{ }^{*} \mathrm{p}<0.05$ 
landscape sites (site 1 showed about four times higher TURB and $17 \%$ lower WIND than site 2 ) than between the forests sites (site 3 showed about $55 \%$ smaller TURB and $13 \%$ higher WIND than site 4 ).

\section{Species traits: VTERM and HAC}

VTERM had an effect on LDD in both vegetation types (Table 1). A significant effect of HAC on LDD was

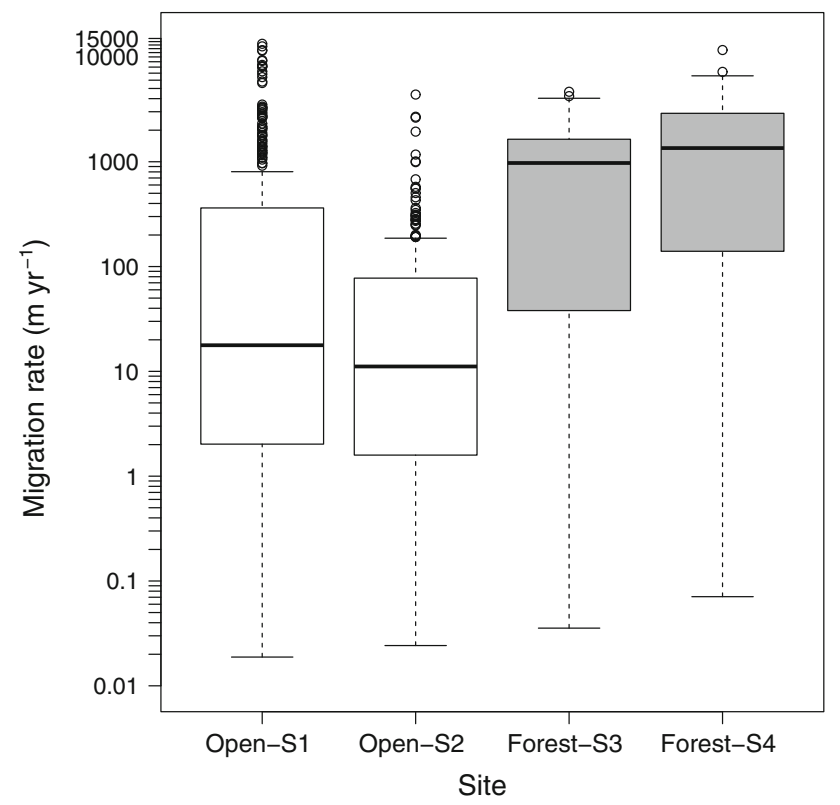

Fig. 1 Migration rates for four sites of the vegetation types open landscape (S1, S2) and forest (S3, S4). Each box plot represents 306 migration rates (17 weeks $\times 18$ species). Migration rate is shown on a log-scaled axis found only in open landscape sites $(\mathrm{p}<0.001)$ while the interaction of VTERM and HAC was significant in both vegetation types. Low median migration rates (of only few $\mathrm{m}_{\text {year }}{ }^{-1}$ ) were found for open landscape species with VTERM $\geq 1.6 \mathrm{~m} \mathrm{~s}^{-1}$ and for forest species with VTERM $=3.2 \mathrm{~m} \mathrm{~s}^{-1}$ (Fig. 2).

Between-year variability of LDD and interaction with VTERM

A significant between-year effect on LDD was only found in forest sites (Table 3; Fig. 2b). Absolute between-year differences in LDD increased with decreasing VTERM and were biggest for species with VTERM = $0.1 \mathrm{~m} \mathrm{~s}^{-1}$ and smallest for species with VTERM $=3.2$ $\mathrm{m} \mathrm{s}^{-1}$ (difference in median migration rates: 1501.8 and $0.4 \mathrm{~m}$ year $^{-1}$, respectively). The between-year effect on LDD was different between both forest sites: In forest site 3 the between-year effect on LDD was generally significant (Table 3 ). In contrast, in the forest site 4 the between-year effect on LDD was only significant for species with intermediate and high VTERM (1.6 and $3.2 \mathrm{~m} \mathrm{~s}^{-1}$ ) although for these species absolute differences in median migration rates were only about a few decimetres per year.

Relative between-year differences in TURB were greater in forest site $3(21.6 \%)$ than in site 4 $(0.6 \%)$, whereas between-year differences in WIND were greater in site $4(4.6 \%)$ than in site $3(0.5 \%$; see also Table 2).

In open landscape sites, absolute between-year differences in LDD were only high for species with VTERM $=0.1 \mathrm{~m} \mathrm{~s}^{-1}$ (difference in median migration rates: $457.1 \mathrm{~m}$ year $^{-1}$, see also Fig. $2 \mathrm{a}$ ).

Table 2 Summary table of the meteorological parameters TURB (the proportion of updrafts relevant for long-distance seed dispersal as described in Tackenberg et al. 2003b) and WIND (horizontal wind speed)

\begin{tabular}{|c|c|c|c|c|c|c|c|c|}
\hline \multirow[t]{3}{*}{ Dataset } & \multirow[t]{3}{*}{ Factor } & \multirow[t]{3}{*}{ Vegetation type } & \multirow[t]{3}{*}{ Site } & \multirow[t]{3}{*}{ Year } & \multicolumn{4}{|c|}{ Meteorological parameter } \\
\hline & & & & & \multicolumn{2}{|l|}{ TURB } & \multicolumn{2}{|c|}{ WIND } \\
\hline & & & & & Mean & SD & Mean & $\mathrm{SD}$ \\
\hline 1 & Vegetation type & Open & 1,2 & 2006 & 0.01 & 0.01 & 1.18 & 0.33 \\
\hline 1 & Vegetation type & Forest & 3,4 & 2006 & 0.17 & 0.09 & 1.53 & 0.22 \\
\hline 1 & Site & Open & 1 & 2006 & 0.01 & 0.01 & 1.07 & 0.33 \\
\hline 1 & Site & Open & 2 & 2006 & $<0.01$ & $<0.01$ & 1.29 & 0.30 \\
\hline 1 & Site & Forest & 3 & 2006 & 0.12 & 0.11 & 1.62 & 0.20 \\
\hline 1 & Site & Forest & 4 & 2006 & 0.21 & 0.05 & 1.44 & 0.20 \\
\hline 2 & Year & Open & 1 & 2005 & 0.01 & 0.01 & 1.07 & 0.42 \\
\hline 2 & Year & Open & 1 & 2006 & 0.01 & 0.01 & 1.12 & 0.36 \\
\hline 2 & Year & Open & 2 & 2005 & 0.01 & $<0.01$ & 1.31 & 0.53 \\
\hline 2 & Year & Open & 2 & 2006 & $<0.01$ & $<0.01$ & 1.31 & 0.28 \\
\hline 3 & Year & Forest & 3 & 2005 & 0.15 & 0.10 & 1.60 & 0.30 \\
\hline 3 & Year & Forest & 3 & 2006 & 0.12 & 0.09 & 1.61 & 0.30 \\
\hline 3 & Year & Forest & 4 & 2005 & 0.20 & 0.04 & 1.37 & 0.21 \\
\hline 3 & Year & Forest & 4 & 2006 & 0.20 & 0.04 & 1.43 & 0.25 \\
\hline
\end{tabular}

Mean values and standard deviation (SD) were calculated based on the weekly values of TURB and WIND (in $\mathrm{m} \mathrm{s}^{-1}$ ) provided in Table S2 (electronic supplementary material). The column "Factor" labels the factor considered for quantifying differences in TURB and WIND

Open open landscape 
(a) Open landscape

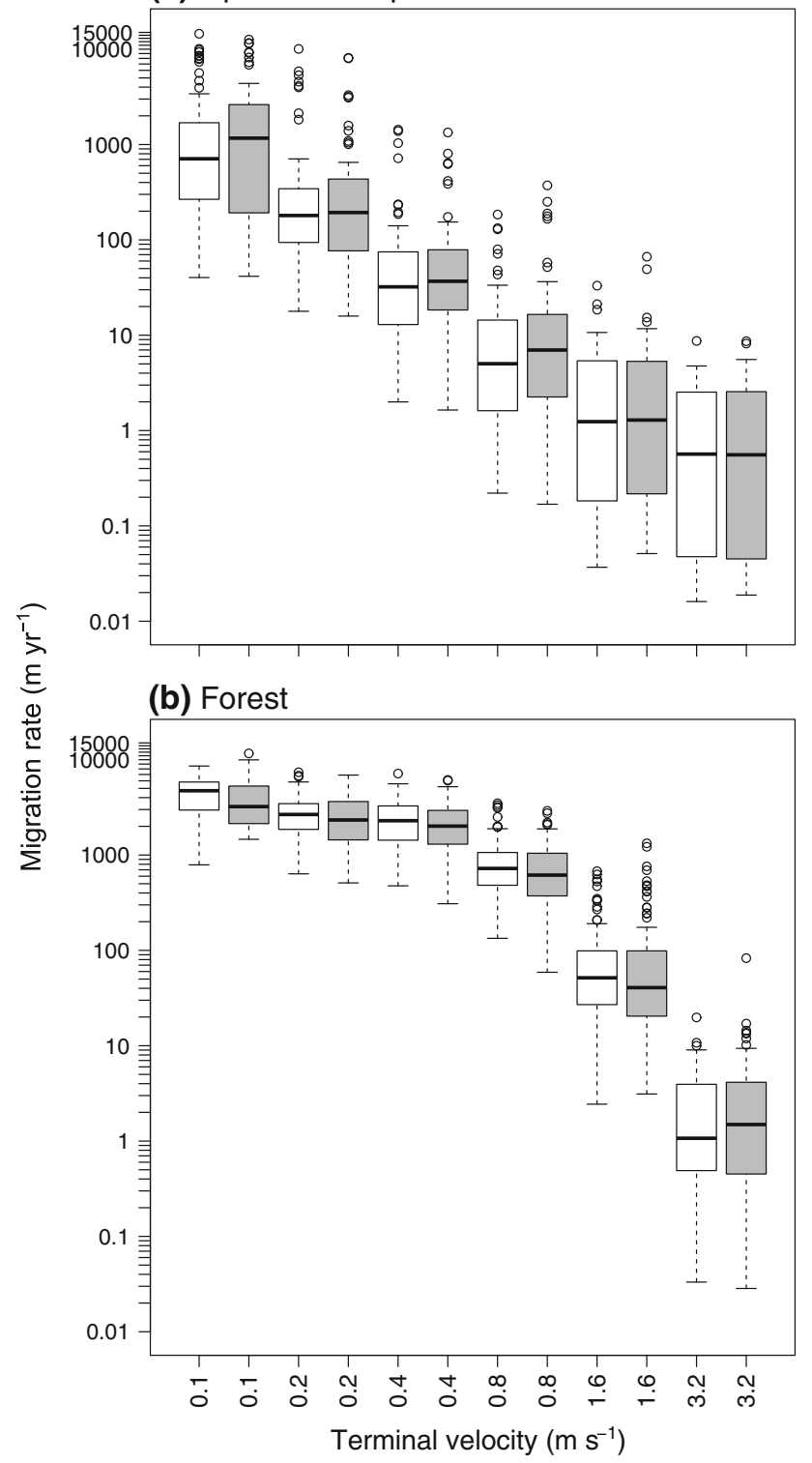

Fig. 2 Migration rates for the years 2005 (white) and 2006 ( grey) in the vegetation type open landscape (a) and forest (b). Each box plot represents 432 (open landscapes) and 684 (forests) migration rates: 18 species $\times 2$ sites $\times 12$ and 19 weeks for open landscape and forest, respectively. Migration rate is shown on a log-scaled axis

The effect of the meteorological parameters WIND and TURB

The effect of WIND and TURB on LDD differed between vegetation types (Table 4; Fig. 3). In forest sites, TURB was positively correlated to LDD for species with VTERM $\geq 0.8 \mathrm{~m} \mathrm{~s}^{-1}$ and the effect of WIND on LDD changed from positive (VTERM $=3.2 \mathrm{~m} \mathrm{~s}^{-1}$ ) to negative (VTERM $\leq 0.4 \mathrm{~m} \mathrm{~s}^{-1}$ ).

In open landscape sites, LDD was positively related to TURB for species with VTERM $\leq 1.6 \mathrm{~m} \mathrm{~s}^{-1}$ and WIND was positively correlated to LDD for species with VTERM $\geq 0.8 \mathrm{~m} \mathrm{~s}^{-1}$.

\section{Discussion}

Plant spread is mainly driven by rare LDD events (Cain et al. 2000; Nathan 2006). Many studies addressing LDD define it either via absolute dispersal distances (for dispersal of aquatic invertebrates by birds e.g. Green and Figuerola 2005), a percentile of dispersal distances (e.g. the 99th percentile of dispersal distances, Soons and Ozinga 2005) or the proportion of dispersal events exceeding a pre-determined reference distance (e.g. Tackenberg 2003). To generate a measure of LDD, we calculated migration rates which are highly sensitive to rare long-distance dispersal events. For instance, migration rates of species with high VTERM may be much lower than migration rates of species with low VTERM. However, these low migration rates represent the longest dispersal events for these species. Hence, these low migration rates are likely to be ecologically relevant, even if they are lower than pre-determined dispersal distances (as commonly used for other measures of LDD). In addition, we exemplarily showed that the migration rates are closely related to an alternative measure of LDD that refers to a pre-determined dispersal distance of $100 \mathrm{~m}$. Thus, we assume that migration rates can be used as a general measure of LDD and refer to the term LDD rather than to migration rates in order to keep the discussion general and simple. However, for addressing specific questions, concerning e.g. LDD in heavily fragmented landscapes, measures of LDD which for example refer to a particular dispersal distance may be more suitable.

\section{Meteorological conditions: the effect of TURB} and WIND

Wind can be a very effective dispersal vector, but only if the duration of the flight of a seed is prolonged by turbulence or updrafts above the vegetation cover (Nathan et al. 2002). Above the vegetation cover, open landscapes and forests generally differ with respect to the surface roughness. Over any surface, the surface drag generates vertical gradients in horizontal wind velocity and sheer-driven eddies. Above the forest canopy, where surface roughness often is higher, the surface drag is stronger and generates more shear-driven turbulence than e.g. above the vegetation cover of open landscapes (Stull 1988; Finnigan and Kaimal 1994). Everywhere where the sun is providing energy to the surface, thermally driven buoyant eddies are generated by heat fluxes with warmer and lighter air near the surface (Stull 1988; Finnigan and Kaimal 1994). Heat fluxes may be weaker above forests than above open landscapes, as more of the solar energy is likely to be converted into fluxes of water vapour. Thus, above open landscapes surface characteristics enhancing the generation of vertical turbulence can be suggested to be more often found than above forest canopies (Stull 1988). Thermally driven 
Table 3 Summary statistics of four generalised linear models of the gamma error distribution family

\begin{tabular}{|c|c|c|c|c|}
\hline & Estimate & Std. error & t-value & p-value \\
\hline \multicolumn{5}{|c|}{ Open landscape: Site 1} \\
\hline VTERM_0.1 & 0.00027 & 0.000056 & 4.837 & $<0.001^{* * *}$ \\
\hline VTERM_0.2 & 0.00058 & 0.00018 & 3.137 & $0.002 * *$ \\
\hline VTERM $^{-0} 0.4$ & 0.0055 & 0.0012 & 4.606 & $<0.001^{* * *}$ \\
\hline VTERM ${ }^{-0} 0.8$ & 0.029 & 0.0061 & 4.793 & $<0.001^{* * *}$ \\
\hline VTERM_1.6 & 0.198 & 0.041 & 4.831 & $<0.001^{* * *}$ \\
\hline VTERM_3.2 & 0.802 & 0.16 & 4.836 & $<0.001^{* * *}$ \\
\hline \multicolumn{5}{|c|}{ Open landscape: Site 2} \\
\hline VTERM_0.1 & 0.0019 & 0.00029 & 6.832 & $<0.001^{* * *}$ \\
\hline VTERM 0.2 & 0.0048 & 0.0010 & 4.644 & $<0.001^{* * *}$ \\
\hline VTERM_0.4 & 0.025 & 0.004 & 6.317 & $<0.001^{* * *}$ \\
\hline VTERM $^{-} 0.8$ & 0.136 & 0.020 & 6.733 & $<0.001^{* * *}$ \\
\hline VTERM ${ }^{-1} 1.6$ & 0.457 & 0.067 & 6.802 & $<0.001^{* * *}$ \\
\hline VTERM_3.2 & 1.146 & 0.168 & 6.820 & $<0.001^{* * *}$ \\
\hline \multicolumn{5}{|l|}{ Forest: Site 3} \\
\hline VTERM_0.1 & 0.00028 & 0.000039 & 7.316 & $<0.001^{* * *}$ \\
\hline VTERM_0.2 & 0.00019 & 0.000066 & 2.951 & $0.003^{* *}$ \\
\hline VTERM 0.4 & 0.00018 & 0.000065 & 2.837 & $0.005^{* *}$ \\
\hline VTERM_0.8 & 0.00078 & 0.00012 & 6.329 & $<0.001^{* * *}$ \\
\hline VTERM_1.6 & 0.0082 & 0.00090 & 9.083 & $<0.001^{* * *}$ \\
\hline VTERM $^{-} 3.2$ & 0.495 & 0.052 & 9.467 & $<0.001^{* * *}$ \\
\hline Year & 0.00012 & 0.000053 & 2.250 & $0.025^{*}$ \\
\hline \multicolumn{5}{|l|}{ Forest: Site 4} \\
\hline VTERM_0.1 & 0.00018 & 0.000024 & 7.566 & $<0.001^{* * *}$ \\
\hline VTERM-0.2 & 0.00010 & 0.000045 & 2.289 & $0.022 *$ \\
\hline VTERM_0.4 & 0.00017 & 0.000052 & 3.234 & $0.001 * *$ \\
\hline VTERM-0.8 & 0.0011 & 0.00017 & 6.436 & $<0.001^{* * *}$ \\
\hline VTERM_1.6 & 0.014 & 0.0019 & 7.468 & $<0.001^{* * *}$ \\
\hline VTERM $^{-} 3.2$ & 0.525 & 0.069 & 7.563 & $<0.001^{* * *}$ \\
\hline Year & 0.0000034 & 0.000034 & 0.098 & 0.922 \\
\hline VTERM_0.2:Year & -0.0000044 & 0.000063 & -0.070 & 0.944 \\
\hline VTERM_0.4:Year & 0.000014 & 0.000075 & 0.185 & 0.853 \\
\hline VTERM_0.8:Year & -0.000017 & 0.00024 & -0.071 & 0.943 \\
\hline VTERM_1.6:Year & -0.0054 & 0.0022 & -2.478 & $0.013^{*}$ \\
\hline VTERM_3.2:Year & -0.287 & 0.076 & -3.768 & $<0.001^{* * *}$ \\
\hline
\end{tabular}

Each model analyses the between-year effect on migration rates for one site of the vegetation types open landscape and forest. Models are based on 432 and 684 migration rates: 18 species $\times 1$ site $\times 2$ years $\times 12$ and 19 weeks for analysis of open landscape and forest, respectively. The table includes estimates, standard errors (Std. Error), t- and corresponding p-values for all significant interactions and variables. Between-year differences were only significant when the variable 'year' or its interaction with seed terminal velocity (VTERM) showed a significant effect on migration rates

Different symbols indicate significant levels with $* * * \mathrm{p}<0.001, * * \mathrm{p}<0.01$ and $* \mathrm{p}<0.05$

updrafts generally tend to generate eddies that provide lift for longer and continuous periods than shear driven turbulence produced by strong winds. In summary, open landscapes and forests differ with respect to the relative distribution of turbulence and its resident time above the vegetation cover. Above most open landscapes, we suggest that more thermally driven buoyant eddies, providing lift for longer periods, are generated. By contrast, above forest canopies we suggest high wind speeds tend to produce strong, but more intermittent, shear driven turbulence (Finnigan and Kaimal 1994).

We found both TURB and WIND to be related to LDD in both vegetation types. In both vegetation types the strength of the predominantly positive relationship between WIND and LDD generally increased with VTERM. Interestingly, even WIND showed a negative effect on LDD of tree species with VTERM $\leq 0.4 \mathrm{~m}$ $\mathrm{s}^{-1}$. This negative effect of WIND on LDD of tree species with low VTERM could possibly be explained by the tendency of shear-driven turbulence above the canopy becoming more intermittent when wind velocity is increasing. Although shear-driven turbulence generated by strong winds can be strong, its intermittency probably makes it less effective for LDD by wind. Furthermore, species interactions with TURB differed considerably between vegetation types. In forest sites, the strength of the positive relationship between TURB and LDD generally increased with VTERM and was significant for species VTERM $\geq 0.8 \mathrm{~m} \mathrm{~s}^{-1}$. For tree species with morphological adaptations to dispersal by wind (e.g. species with winged seeds like Pinus nigra $\left(\right.$ VTERM $\left.=0.81 \mathrm{~m} \mathrm{~s}^{-1}\right)$ and Fraxinus excelsior (VTERM $=1.58 \mathrm{~m} \mathrm{~s}^{-1}$ ) we suggest that TURB plays an important role for LDD. For tree species with high VTERM (e.g. Alnus glutinosa with VTERM $=2.77$ $\mathrm{m} \mathrm{s}^{-1}$ ) we found both WIND and TURB to have a significant effect on LDD although it yields in only small dispersal distances and may thus not be ecologically relevant at all. 
Table 4 Correlations between migration rates and both studied meteorological parameters TURB (the proportion of updrafts relevant for long-distance seed dispersal as described in Tackenberg et al. 2003b) and WIND (horizontal wind speed)

\begin{tabular}{|c|c|c|c|c|c|}
\hline \multirow[t]{3}{*}{ Vegetation type } & \multirow[t]{3}{*}{ VTERM $\left(\mathrm{m} \mathrm{s}^{-1}\right)$} & \multicolumn{4}{|c|}{ Meteorological parameter } \\
\hline & & \multicolumn{2}{|l|}{ TURB } & \multicolumn{2}{|l|}{ WIND } \\
\hline & & Spearman's $\rho$ & p-value & Spearman's $\rho$ & p-value \\
\hline Open landscape & 0.1 & 0.557 & $<0.001 * * *$ & 0.018 & 0.866 \\
\hline Open landscape & 0.2 & 0.641 & $<0.001^{* * *}$ & 0.075 & 0.477 \\
\hline Open landscape & 0.4 & 0.482 & $<0.001 * * *$ & 0.179 & 0.090 \\
\hline Open landscape & 0.8 & 0.502 & $<0.001 * * *$ & 0.334 & $0.001 * *$ \\
\hline Open landscape & 1.6 & 0.383 & $<0.001 * * *$ & 0.418 & $<0.001 * * *$ \\
\hline Open landscape & 3.2 & 0.121 & 0.252 & 0.497 & $<0.001 * * *$ \\
\hline Forest & 0.1 & 0.136 & 0.178 & -0.374 & $<0.001 * * *$ \\
\hline Forest & 0.2 & 0.133 & 0.187 & -0.378 & $<0.001 * * *$ \\
\hline Forest & 0.4 & 0.120 & 0.237 & -0.452 & $<0.001 * * *$ \\
\hline Forest & 0.8 & 0.522 & $<0.001 * * *$ & -0.079 & 0.433 \\
\hline Forest & 1.6 & 0.539 & $<0.001^{* * *}$ & 0.197 & 0.051 \\
\hline Forest & 3.2 & 0.401 & $<0.001 * * *$ & 0.479 & $<0.001 * * *$ \\
\hline
\end{tabular}

Correlation analyses were carried out for each seed terminal velocity (VTERM) and each vegetation type and based on 546 and 594 migration rates and corresponding meteorological parameters for open landscape and forest, respectively

Different symbols indicate significance levels with $* * * p<0.001, * * p<0.01$ and $* \mathrm{p}<0.05$
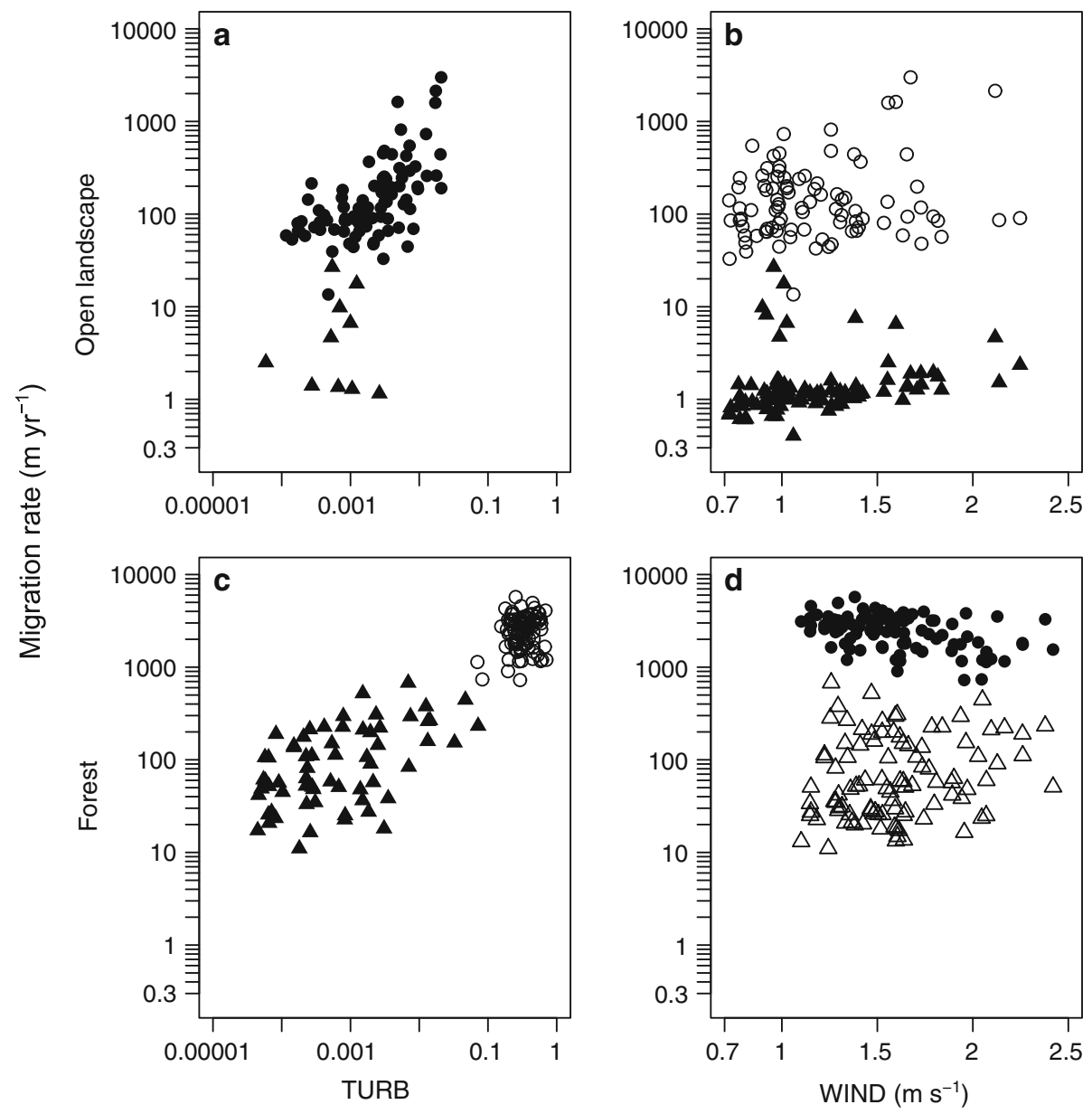

Fig. 3 Relationship between migration rates and both studied meteorological parameters TURB (the proportion of updrafts relevant for long-distance seed dispersal as described in Tackenberg et al. 2003b) and WIND (horizontal wind speed). The relationship is shown for selected species from the open landscape and forest with seed terminal velocity $=0.2 \mathrm{~m} \mathrm{~s}^{-1}$ (circles) and $1.6 \mathrm{~m} \mathrm{~s}^{-1}$

(triangles). Full symbols indicate significant correlations between migration rates and the respective meteorological measure (Table 4). The plots show 182 and 198 migration rates and corresponding meteorological parameters for open landscape and forest, respectively. Migration rate and TURB are shown on a logscaled axis 
Our results from open landscape sites suggest that the strength of the positive relationship between TURB and LDD generally decreases with VTERM. Thus, we propose updrafts to play a predominant role for LDD of open landscape species with low and intermediate VTERM which is in strong accordance with previous findings made by Tackenberg et al. (2003b) and was also empirically observed (Tackenberg 2003, see also "Modelling wind dispersal using PAPPUS").

For species with higher VTERM, LDD was stronger affected by WIND than by TURB in both vegetation types. This particular role of WIND could possibly explained by the tendency of shear driven turbulence being stronger (even though more intermittent) than thermally driven turbulence.

\section{Differences between vegetation types and sites}

Our results show that LDD was significantly greater above the canopy of the forest sites than above the open landscape sites. Especially in fragmented landscapes, open landscapes are typically surrounded by aboveground barriers like e.g. forests, hedges or shrubs. Such aboveground barriers are supposed to decrease LDD by decreasing wind speed (Nathan et al. 2008). By contrast, forests hardly exhibit higher aboveground barriers decreasing wind speed above their canopy (Stull 1988). Hence, lower LDD above the open landscape sites may be due to aboveground barriers surrounding them. By analysing plant communities in The Netherlands, Ozinga et al. (2004) showed a clear positive relationship between increasing openness of the vegetation and the potential of species' LDD by wind.

Our results indicate that somewhat greater relative differences in LDD between open landscape sites than between forest sites may be explained by greater relative between-site differences in TURB and WIND in open landscape sites than in forest sites. However, as the analysis of the between-site effect was performed only for two sites, the obtained differences between sites cannot be referred to particular site characteristics and should not be generalized from our study.

\section{The effect of the species traits VTERM and HAC}

Our result of the significant importance of VTERM on LDD by wind is supported by early findings of Green (1980) and subsequent studies (Tackenberg et al. 2003a; Wright et al. 2008). The effect of HAC was not significant in forest sites, but in open landscape sites. Hence, tall species from open landscapes like e.g. Typha latifolia (VTERM $=0.11 \mathrm{~m} \mathrm{~s}^{-1}$, all VTERM data mentioned in the following retrieved from Hintze et al. 2013) have a considerably higher probability to exhibit LDD by wind than low-growing species with similar VTERM as e.g. Tussilago farfara $\left(\right.$ VTERM $=0.17 \mathrm{~m} \mathrm{~s}^{-1}$ ).
However, HAC must be interpreted differentially when comparing herbs and forest trees: It seems rather unrealistic that a variability of $1.5 \mathrm{~m}$ in HAC occurs within one small growing herb-species (much less within individuals), while such variability can easily be observed within single tree individuals. From an evolutionary point of view it would therefore be interesting to investigate, whether lowering VTERM or increasing $\mathrm{HAC}$ is a more successful evolutionary process of plant species in response to selection on LDD. In a simulation study regarding wind dispersal in grasslands species Soons et al. (2004) found a greater effect of release height on LDD in comparison to VTERM when considering the magnitude of observed within-species variability of these traits.

For open landscape species with intermediate and high VTERM as well as for forest species with high VTERM wind dispersal yielded in only very low dispersal rates. Hence, we suggest that for these species other vectors than wind play a bigger role for seed dispersal.

\section{Between-year variability}

Regarding forest sites, our results indicate that betweenyear differences in LDD are significant. The betweenyear effect was generally significant in site 3 . By contrast, in site 4 only species with intermediate and high VTERM (e.g. Fraxinus excelsior and Alnus glutinosa exhibiting a VTERM of 1.58 and $2.77 \mathrm{~m} \mathrm{~s}^{-1}$, respectively) showed a significant between-year effect on LDD (Table 3). Despite the significance of the between-year effect in site 4 , its ecological relevance is very likely to be only minor as the absolute between-year differences in LDD were less than few meters only. In agreement with our findings for forest site 3 , considerable between-year variability was also found in low VTERM and wind dispersed Betula alleghaniensis and Pinus halepensis (Houle 1998; Nathan et al. 2000, respectively). For species with intermediate VTERM, Gomez-Aparicio et al. (2007) found no considerable between-year variability in Mediterranean Acer opalus (VTERM $=1.04$ $\mathrm{m} \mathrm{s}^{-1}$, unpublished data). In open landscape sites, the between-year differences of LDD were relatively small for most species (except for species with VTERM = $0.1 \mathrm{~m} \mathrm{~s}^{-1}$, Fig. 2a) and not significant.

Our results from forest sites suggest that site-specific characteristics seem to play an important role for between-year variability in LDD. This finding is probably due to site-specific differences in frequency and magnitude of meteorological conditions favouring uplift of seeds. Shear-induced uplifting of tree seeds is known to be influenced by the density of the canopy and vegetation cover (Bohrer et al. 2008) which is likely to differ between the forest sites analysed in this study. In fact, for the forest sites, the observed site-specific betweenyear differences in LDD might be explained by betweenyear differences in the occurrence and strength of 
meteorological parameters: between-year differences in TURB were greater in forest site 3 , whereas betweenyear differences in WIND were greater in site 4 . This pattern tentatively indicates, that the general betweenvariability in LDD for site 3 may be explained by considerable between-year variability in TURB. By contrast, the pronounced variability of LDD for species with VTERM $\geq 1.6 \mathrm{~m} \mathrm{~s}^{-1}$ in site 4 could be due to greater between-year differences in WIND.

Kuparinen et al. (2009) found biggest differences in LDD for species with low VTERM. Likewise, our results show that absolute between-year differences in LDD in both vegetation types were biggest for species with low VTERM. Hence, the variability at the betweenyear time scale is likely to affect spread rates of species with low VTERM to a greater extent than spread rates of species with high VTERM.

Although we put considerable effort in collecting wind data from different years and different sites, the merged datasets allowed conducting a reliable betweenyear analysis for the years 2005 and 2006, only. Consequently, the results from the between-year analysis should not be generalized.

\section{Conclusions and outlook}

To conclude, we found that LDD was higher in forests than in open landscapes. Forests also showed greater between-year variability in LDD. In both vegetation types, VTERM had an effect on LDD, while the effect of HAC was significant only in the open landscape. Our results show considerable differences in how TURB and WIND affected LDD between species and vegetation types. Until now, such differences - if recognized at all - have often been attributed to differences in model performance. However, to further elaborate the role of the considered parameters, and their variability and interaction on LDD by wind, additional studies comprising even data sets from further study sites and larger temporal scales (e.g. decades of environmental data) seem vitally important. As the availability of wind shows a considerable within-year variation, the effects of TURB and WIND on LDD are likely to differ in the course of the year. By focussing our analysis on the same periods of the year we prevented comprising biased data with respect to within-year variability of TURB and WIND. In our study, seed abscission was not addressed. Seed abscission can follow a seasonal pattern and positively affect LDD when it preferably occurs during periods of prolonged updrafts (Maurer et al. 2013). Likewise, seed abscission during high wind speed events was shown to positively affect LDD (Pazos et al. 2013) and thereby decreasing differences in LDD between low and high wind speed environments. Due to the exclusion of seed abscission, our results could partially underestimate LDD, particularly in the open landscape (as a low wind speed environment). For future studies, the effect of the phenology of dispersal on LDD should be ana- lysed in detail promising deeper understanding of its role for species' LDD. For example, LDD of forest species dispersing in summer time (e.g. Ulmus laevis) vs. LDD of forest species dispersing in winter time (e.g. Acer platanoides) is likely to be differentially affected by meteorological parameters, even if VTERM of the species is quite similar.

Acknowledgments We like to thank two anonymous reviewers who greatly improved the manuscript with constructive suggestions, particularly comments on the processes of turbulence-generation. Thanks also to I. Lehner and T. Grünwald for supplying turbulence data. Thanks to Daniel Jordan Grobbel-Rank for linguistic corrections on the manuscript. The present study was conducted at the Goethe University, Frankfurt a. M., and funded by the German Research Foundation DFG (TA 311/2-3) as well as by the research funding programme "LOEWE-Landes-Offensive zur Entwicklung Wissenschaftlich-ökonomischer Exzellenz" of Hesse's Ministry of Higher Education, Research, and the Arts.

Open Access This article is distributed under the terms of the Creative Commons Attribution License which permits any use, distribution, and reproduction in any medium, provided the original author(s) and the source are credited.

\section{References}

Bohrer G, Katul GG, Nathan R, Walko RL, Avissar R (2008) Effects of canopy heterogeneity, seed abscission and inertia on wind-driven dispersal kernels of tree seeds. J Ecol 96:569-580

Cain ML, Milligan BG, Strand AE (2000) Long-distance seed dispersal in plant populations. Am J Bot 87:1217-1227

Clark JS, Fastie C, Hurtt G, Jackson ST, Johnson C, King GA, Lewis M, Lynch J, Pacala S, Prentice C, Schupp EW, Webb T, Wyckoff P (1998) Reid's paradox of rapid plant migration-dispersal theory and interpretation of paleoecological records. Bioscience 48:13-24

Clark JS, Lewis M, Horvath L (2001) Invasion by extremes: population spread with variation in dispersal and reproduction. Am Nat 157:537-554

Crawley MJ (2007) The R Book. Wiley \& Sons Ltd, Chichester. doi:10.1002/9780470515075.ch 1

Cunze S, Heydel F, Tackenberg O (2013) Are plant species able to keep pace with the rapidly changing climate? PLoS One 8:e67909. doi:10.1371/journal.pone.0067909

Finnigan JJ, Kaimal JC (1994) Atmospheric boundary layer flows: their structure and measurement. Oxford University Press, New York

Fort KP, Richards JH (1998) Does seed dispersal limit initiation of primary succession in desert playas? Am $\mathbf{J}$ Bot 85:1722-1731

Gomez-Aparicio L, Gomez JM, Zamora R (2007) Spatiotemporal patterns of seed dispersal in a wind-dispersed Mediterranean tree (Acer opalus subsp. granatense): implications for regeneration. Ecography 30:13-22. doi:10.1111/j.0906-7590.2007.04658.x

Green DS (1980) The terminal velocity and dispersal of spinning samaras. Am J Bot 67:1218-1224

Green AJ, Figuerola J (2005) Recent advances in the study of longdistance dispersal of aquatic invertebrates via birds. Divers Distrib 11:149-156. doi:10.1111/j.1366-9516.2005.00147.x

Greene DF (2005) The role of abscission in long-distance seed dispersal by the wind. Ecology 86:3105-3110

Greene DF, Calogeropoulos C (2002) Measuring and modelling seed dispersal of terrestrial plants. In: Bullock JM, Kenward RE, Hails RS (eds) Dispersal ecology: 42nd Symposium of the British Ecological Society. Blackwell Press, Oxford, pp 3-23

Greene DF, Quesada M (2011) The differential effect of updrafts, downdrafts and horizontal winds on the seed abscission of Tragopogon dubius. Funct Ecol 25:468-472. doi:10.1111/j.13652435.2010.01788.x 
Grünwald T, Bernhofer C (2007) A decade of carbon, water and energy flux measurements of an old spruce forest at the Anchor Station Tharandt. Tellus B 59:387-396. doi:10.1111/j.1600-0889. 2007.00259.x

Higgins SI, Lavorel S, Revilla E (2003) Estimating plant migration rates under habitat loss and fragmentation. Oikos 101:354-366

Hintze C, Heydel F, Hoppe C, Cunze S, König A, Tackenberg O (2013) $\mathrm{D}^{3}$ : The dispersal and diaspore database - baseline data on seed dispersal. Perspect Plant Ecol 15:180-192. doi: 10.1016/j.ppees.2013.02.001

Horn HS, Nathan R, Kaplan SR (2001) Long-distance dispersal of tree seeds by wind. Ecol Res 16:877-885

Horn S, Raabe A, Will H, Tackenberg O (2012) TurbSeed-a model for wind dispersal of seeds in turbulent currents based on publicly available climate data. Ecol Model 237:1-10. doi: 10.1016/j.ecolmodel.2012.04.009

Houle G (1998) Seed dispersal and seedling recruitment of Betula alleghaniensis: spatial inconsistency in time. Ecology 79:807-818. doi:10.1890/0012-9658(1998)079[0807:SDASRO]2.0. $\mathrm{CO} ; 2$

Jongejans E, Schippers P (1999) Modeling seed dispersal by wind in herbaceous species. Oikos 87:362-372

Kawecki TJ, Ebert D (2004) Conceptual issues in local adaptation. Ecol Lett 7:1225-1241

Kuparinen A (2006) Mechanistic models for wind dispersal. Trends Plant Sci 11:296-301

Kuparinen A, Katul G, Nathan R, Schurr FM (2009) Increases in air temperature can promote wind-driven dispersal and spread of plants. Proc R Soc Lond Ser B 276:3081-3087

Latzel V, Klimešová J, Doležal J, Pyšek P, Tackenberg O, Prach K (2011) The association of dispersal and persistence traits of plants with different stages of succession in central European man-made habitats. Folia Geobot 46:289-302

Lehner I (2008) Carbon balance of a rain-fed maize field. PhD thesis, University of Basel, Institute of Meteorology, Climatology and Remote Sensing, Basel. doi:10.5451/unibas-004690312

Maurer KD, Bohrer G, Medvigy D, Wright SJ, Thompson K (2013) The timing of abscission affects dispersal distance in a wind-dispersed tropical tree. Funct Ecol 27:208-218. doi: $10.1111 / 1365-2435.12028$

Mazzoni R (1996) Turbulenzstruktur im gestörten Nachlauf einer künstlichen Oberflächenmodifikation. Ein Feldexperiment. Zür Geogr Schr 60. Geographisches Institut ETH Zürich. DOI 10.3929/ethz-a-001638108

McCartney HA (1990) Dispersal mechanisms through the air. In: Bunce RGH, Howard DC (eds) Species dispersal in agricultural habitats. Belhaven Press, London, pp 133-158

Nathan R (2006) Long-distance dispersal of plants. Science 313:786-788. doi:10.1126/science. 1124975

Nathan R, Safriel UN, Noy-Meir I, Schiller G (1999) Seed release without fire in Pinus halepensis, a Mediterranean serotinous wind-dispersed tree. J Ecol 87:659-669

Nathan R, Safriel UN, Noy-Meir I, Schiller G (2000) Spatiotemporal variation in seed dispersal and recruitment near and far from Pinus halepensis trees. Ecology 81:2156-2169. doi:10.1890/ 0012-9658(2000)081[2156:SVISDA]2.0.CO;2

Nathan R, Katul GG, Horn HS, Thomas SM, Oren R, Avissar R, Pacala SW, Levin SA (2002) Mechanisms of long-distance dispersal of seeds by wind. Nature 418:409-413

Nathan R, Schurr FM, Spiegel O, Steinitz O, Trakhtenbrot A, Tsoar A (2008) Mechanisms of long-distance seed dispersal. Trends Ecol Evol 23:638-647

Nathan R, Katul GG, Bohrer G, Kuparinen A, Soons MB, Thompson SE, Trakhtenbrot A, Horn HS (2011) Mechanistic models of seed dispersal by wind. Theor Ecol 4:113-132
Neilson RP, Pitelka LF, Solomon AM, Nathan R, Midgley GF, Fragoso JMV, Lischke H, Thompson K (2005) Forecasting regional to global plant migration in response to climate change. Bioscience 55:749-759

Normand S, Ricklefs RE, Skov F, Bladt J, Tackenberg O, Svenning JC (2011) Postglacial migration supplements climate in determining plant species ranges in Europe. Proc R Soc Lond Ser B 278:3644-3653

Öster M, Ask K, Römermann C, Tackenberg O, Eriksson O (2009) Plant colonization of ex-arable fields from adjacent species-rich grasslands: the importance of dispersal vs. recruitment ability. Agric Ecosyst Environ 130:93-99. doi:10.1016/j.agee.2008. 12.005

Ozinga WA, Bekker RM, Schaminee JHJ, van Groenendael JM (2004) Dispersal potential in plant communities depends on environmental conditions. J Ecol 92:767-777

Parmesan C, Yohe G (2003) A globally coherent fingerprint of climate change impacts across natural systems. Nature 421:37-42. doi:10.1038/nature01286

Pazos GE, Greene DF, Katul G, Bertiller MB, Soons MB, Jongejans E (2013) Seed dispersal by wind: towards a conceptual framework of seed abscission and its contribution to long-distance dispersal. J Ecol 101:889-904. doi:10.1111/1365-2745.12103

Pitelka LF, Gardner RH, Ash J, Berry S, Gitay H, Noble IR, Saunders A, Bradshaw RHW, Brubaker L, Clark JS, Davis MB, Sugita S, Dyer JM, Hengeveld R, Hope G, Huntley B, King GA, Lavorel S, Mack RN, Malanson GP, McGlone M, Prentice IC, Rejmanek M (1997) Plant migration and climate change: a more realistic portrait of plant migration is essential to predicting biological responses to global warming in a world drastically altered by human activity. Am Sci 85:464-473

Prescher AK, Grünwald T, Bernhofer C (2010) Land use regulates carbon budgets in eastern Germany: from NEE to NBP. Agric For Meteorol 150:1016-1025

R Core Team (2012) R: A language and environment for statistical computing. R Foundation for Statistical Computing, Vienna, Austria. URLhttp://www.r-project.org

Rykiel EJ (1996) Testing ecological models: the meaning of validation. Ecol Model 90:229-244. doi:10.1016/0304-3800(95)00152-2

Schippers P, Jongejans E (2005) Release thresholds strongly determine the range of seed dispersal by wind. Ecol Model 185:93-103

Soons MB, Ozinga WA (2005) How important is long-distance seed dispersal for the regional survival of plant species? Divers Distrib 11:165-172

Soons MB, Heil GW, Nathan R, Katul GG (2004) Determinants of long-distance seed dispersal by wind in grasslands. Ecology 85:3056-3068

Stull RB (1988) An introduction to boundary layer meteorology. Atmospheric sciences library, Kluver Academic Publishers, Dordrecht

Tackenberg O (2003) Modeling long-distance dispersal of plant diaspores by wind. Ecol Monogr 73:173-189

Tackenberg O, Stöcklin J (2008) Wind dispersal of alpine plant species: a comparison with lowland species. J Veg Sci 19:109-118

Tackenberg O, Poschlod P, Bonn S (2003a) Assessment of wind dispersal potential in plant species. Ecol Monogr 73:191-205

Tackenberg O, Poschlod P, Kahmen S (2003b) Dandelion seed dispersal: the horizontal wind speed does not matter for longdistance dispersal - it is updraft! Plant Biol 5:451-454

Wright SJ, Trakhtenbrot A, Bohrer G, Detto M, Katul GG, Horvitz N, Muller-Landau HC, Jones FA, Nathan R (2008) Understanding strategies for seed dispersal by wind under contrasting atmospheric conditions. Proc Natl Acad Sci USA 105:19084-19089 